City University of New York (CUNY) CUNY Academic Works

\title{
Bullying, Depression, and Suicidality in Adolescents
}

Anat Brunstein-Klomek

Columbia University

Frank Marrocco

Columbia University

Marjorie Kleinman

Columbia University

Irvin Sam Schonfeld

CUNY Graduate Center

Madelyn S. Gould

Columbia University

\section{How does access to this work benefit you? Let us know!}

More information about this work at: https://academicworks.cuny.edu/cc_pubs/309

Discover additional works at: https://academicworks.cuny.edu

This work is made publicly available by the City University of New York (CUNY).

Contact: AcademicWorks@cuny.edu 


\title{
Bullying, Depression, and Suicidality in Adolescents
}

\author{
ANAT BRUNSTEIN KLOMEK, Ph.D., FRANK MARROCCO, Ph.D., \\ MARJORIE KLEINMAN, M.S., IRVIN S. SCHONFELD, PH.D., M.P.H, \\ AND MADELYN S. GOULD, PH.D., M.P.H.
}

\begin{abstract}
Objective: To assess the association between bullying behavior and depression, suicidal ideation, and suicide attempts among adolescents. Method: A self-report survey was completed by 9th- through 12th-grade students $(n=2342)$ in six New York State high schools from 2002 through 2004. Regression analyses were conducted to examine the association between being victimized and bullying others with depression, ideation, and attempts. Results: Approximately $9 \%$ of the sample reported being victimized frequently, and $13 \%$ reported bullying others frequently. Frequent exposure to victimization or bullying others was related to high risks of depression, ideation, and suicide attempts compared with adolescents not involved in bullying behavior. Infrequent involvement in bullying behavior also was related to increased risk of depression and suicidality, particularly among girls. The findings indicate that both victims and bullies are at high risk and that the most troubled adolescents are those who are both victims and bullies. Psychopathology was associated with bullying behavior both in and away from school. Conclusions: Victimization and bullying are potential risk factors for adolescent depression and suicidality. In evaluations of students involved in bullying behavior, it is important to assess depression and suicidality. J. Am. Acad. Child Adolesc. Psychiatry, 2007;46(1):40-49. Key Words: bully, victimization, depression, suicide.
\end{abstract}

Nearly one third of 6th through 10th graders in the United States report moderate or frequent involvement in bullying, whether as a bully (13.0\%), a victim $(10.6 \%)$, or both (6.3\%; Nansel et al., 2001). Although bullying behavior declines as children get older (Olweus, 1991), it is still a prevalent problem among high school students (e.g., Kaltiala-Heino et al., 1999; Nansel et al., 2001). Harris (2005) found that $20 \%$ to $30 \%$ of the students in grades 8 through 12 report

Accepted July 3, 2006.

Drs. Brunstein Klomek, Marrocco, and Gould, and Ms. Kleinman are with the Division of Child and Adolescent Psychiatry, Columbia University; Dr. Schonfeld is with City College, City University of New York, and the Child Psychiatry Research Training Program, Columbia University; Dr. Gould is also with the New York State Psychiatric Institute.

This project was supported by National Institute of Mental Health grant RO1-MH64632.

Correspondence to Madelyn S. Gould, Ph.D., M.P.H., Division of Child \& Adolescent Psychiatry, Department of Psychiatry, Columbia University/NYSPI, 1051 Riverside Drive, Unit 72, New York, NY 10032; e-mail: GouldM@ childpsych.columbia.edu.

0890-8567/07/4601-0040@2006 by the American Academy of Child and Adolescent Psychiatry.

DOI: 10.1097/01.chi.0000242237.84925.18 frequent involvement in bullying incidents as either a victim or a bully.

The differentiation between bullies, victims, and bully-victims has been emphasized in the examination of the association of bullying behavior and psychopathology (Forero et al., 1999; Kaltiala-Heino et al., 2000; Nansel et al., 2001). In studies examining the relationship between bullying and depression, victims were found to manifest more depressive symptoms and psychological distress than nonvictims (Hawker and Boulton, 2000; Kumpulainen and Rasanen, 2000; Kumpulainen et al., 1998; Mills et al., 2004; Neary and Joseph, 1994; Slee, 1995; van der Wal et al., 2003; Williams et al., 1996). Findings pertaining to bullies, however, are less consistent. Some studies did not find an association between being a bully and depression (Camodeca and Goossens, 2005; Fekkes et al., 2004; Juvonen et al., 2003), whereas other studies have found that bullies, not just victims, report high levels of depression (Forero et al., 1999; Kaltiala-Heino et al., 1999; Kaltiala-Heino et al., 2000; Kumpulainen et al., 2000; Roland, 2002; Salmon et al., 1998). Those who are both victims and bullies are usually found to be at 
the highest risk for depression (Fekkes et al., 2004; Kaltiala-Heino et al., 1999; Kaltiala-Heino et al., 2000).

Studies reporting on the relationship between bullying and suicidal ideation usually find that victims manifest higher levels of suicidal ideation than nonvictims (Rigby and Slee, 1999; van der Wal et al., 2003). Other studies have found an increased prevalence of suicidal ideation among both victims and bullies (Kaltiala-Heino et al., 1999; Roland, 2002). Most studies assessing the relationship of bullying and suicide attempts have found that victims were more likely to attempt suicide than those not involved (Cleary, 2000; Eisenberg et al., 2003; Mills et al., 2004). Kim and colleagues (2005) were the first to demonstrate an increased risk of suicide attempts among both victims and bullies.

These studies indicate a clear association between bullying and suicidality, but important questions remain unanswered. Most of the studies did not examine suicide attempts and focused on suicidal ideation (Kaltiala-Heino et al., 1999; Rigby et al., 1999; Roland, 2002; van der Wal et al., 2003). Examination of attempts focused on victims and less on bullies or bully-victims (Cleary, 2000; Davies and Cunningham, 1999; Eisenberg et al., 2003; Mills et al., 2004). Moreover, most studies were not conducted in high schools (Ivarsson et al., 2005; Kim et al., 2005; Mills et al., 2004; Roland, 2002; van der Wal et al., 2003) and have not differentiated in-school from outof-school bullying behaviors in their analysis (KaltialaHeino et al., 1999; Nansel et al., 2001; Rigby et al., 1999). There is no study of U.S. adolescents focusing on bullying behavior and suicide attempts among victims, bullies, and bully-victims, nor is there any study differentiating in-school and out-of-school bullying behaviors.

The purpose of this study was to examine the association between bullying behavior and depression, suicidal ideation, and suicide attempts among a large American sample of high school students. Specifically, we examined the prevalence of bullying behavior in and out of school; the association of bullying behavior with depression, suicidal ideation, and suicide attempts by gender; and the impact of the co-occurrence of being bully-victims. We hypothesized that greater exposure to bullying behavior would increase the risk of depression, suicidal ideation, and suicide attempts. We also hypothesized that bullying behavior away from school would be less prevalent but that it would be associated to the same extent with depression and suicidality.

\section{METHOD}

\section{Subjects}

This study targeted adolescents 13 through 19 years of age who were enrolled in 9th through 12th grades in six high schools in Nassau, Suffolk, and Westchester counties in New York. Five schools were public coeducational schools; one was a parochial all-boys school. These schools were part of a study examining whether asking about suicidality during a screening program creates distress or increases suicidal ideation (Gould et al., 2005). This study included 2,341 of 3,635 students (64.4\% participation rate) from fall 2002 through spring 2004. Reasons for nonparticipation included parental refusal (61.9\%), student refusal (14.3\%), and absences $(23.7 \%)$. The ethnic distribution of the participating sample was $80.3 \%$ white, $5.1 \%$ black, $7.3 \%$ Hispanic, $3.8 \%$ Asian, and $3.5 \%$ other. A total of $58.1 \%$ of the students were boys (the inclusion of an all-male parochial school explains the high percentage of boys). The mean age of participating students was 14.8 years (SD 1.2 years). There were no significant differences between participants and nonparticipants in sex, age, and race/ethnicity.

Students were recruited with a waiver of parental consent for parents and active written assent for youth. The recruitment procedures were based on those used in our earlier study (Gould et al., 2004) and were developed in response to what the schools considered would best meet the needs of their community. The present study received Institutional Review Board approval of a waiver of consent based on Federal Regulations [Title 45; Part 46, Article 46.116(d)]. Two mailings with an information sheet describing survey content and procedures, a response form, and a stamped response envelope were sent to parents 6 and 4 weeks before survey administration, providing parents with opportunities to refuse their children's participation and giving them ample pertinent information about the project. Students' written assent was obtained immediately before the survey.

The study procedures, consistent with the Family Educational Rights and Privacy Act and the Protection of Pupil Rights Amendment, were approved by the Institutional Review Board of the New York State Psychiatric Institute/Columbia University Department of Psychiatry.

\section{Measures}

A self-report questionnaire assessed depression, suicidal ideation, suicide attempts, and involvement in bullying behavior both as a bully and as a victim. The assessment time frame was the past 4 weeks, with the exception of measuring lifetime suicide attempts.

Demographic Questionnaire. The demographic questionnaire elicited information on age, grade, gender, racial/ethnic background, and household composition.

Depression. The Beck Inventory (BDI-IA; Beck and Steer, 1993) assessed cognitive, behavioral, affective, and somatic components of depression. Loss of libido was not assessed. The BDI has been used in $>200$ studies, including those with adolescent samples (Roberts et al., 1991; Strober et al., 1981; Teri, 1982). Each 
response ranged from 0 ("symptoms not present") to 3 ("symptom is severe"), with a maximum total score of 60 . A cutoff point of 16 was used to dichotomize BDI scores. This cutoff has correctly classified $81 \%$ of adolescent psychiatric patients with major depressive disorder (Strober et al., 1981) and has been recommended to detect possible depression in normal populations (Beck et al., 1993).

Suicidal Ideation. The Suicide Ideation Questionnaire (SIQ-JR) assesses suicidal thoughts and is designed for large-scale, schoolbased screening of adolescents (Reynolds, 1988). The 15-item SIQJR uses a 7-point Likert-type scale, ranging from 0 ("I never had this thought") to 6 ("This thought was in my mind almost every day"), assessing the frequency of specific suicidal thoughts during the past month. It assesses thoughts related to death and dying, passive and active suicidal ideation, and suicidal intent. Reliability of the SIQ-JR is high, ranging from 0.91 to 0.96 for internal consistency (Keane et al., 1996; Reynolds, 1988; Reynolds and Mazza, 1999) and from 0.87 to 0.93 for test-retest reliability (Reynolds and Mazza, 1999). The SIQ-JR has demonstrated criterion validity (King et al., 1993; Reynolds, 1988; Reynolds, 1990; Reynolds and Mazza., 1999), construct validity in clinical samples (King et al., 1993; King et al., 1996; King et al., 1997; Sibthorpe et al., 1995; Siemen et al., 1994), and predictive validity (Keane et al., 1996). Suicidal ideation was considered serious if the adolescent scored 31 or higher on the SIQ-JR, scored 5 or 6 on two or more of the six "critical" SIQ-JR items (Reynolds, 1988), or responded with either of the two most serious response options of the BDI suicide item.

Suicide Attempt History. Seven questions asking about lifetime and recent suicide attempts were derived from the depression module of the Diagnostic Interview Schedule for Children (Shaffer et al., 2000) and an earlier suicide screen (Shaffer et al., 2004). These items have demonstrated good construct validity (Gould et al., 1998; Shaffer et al., 2004). The assessment of an attempt included questions about occurrences, injuries sustained, medical care sought, and hospitalization (Meehan et al., 1992). The adolescent was considered to have a history of attempt if he or she reported any past attempt, regardless of timing, injury, or medical attention, because there is no evidence that injury or need for medical attention is a clear indication of severity of attempts among adolescents. The availability of a lethal agent is the most significant determination of the lethality of impulsive attempts, whereas intent and severity of psychopathology may make the most important contributions to the lethality of attempts by hopeless, dysphoric adolescents (Brent et al., 1987).

Bullying Behavior. Several questions regarding bullying behavior were derived from the World Health Organization study on youth health (Nansel et al., 2001). Questions about bullying were preceded with the following explanation: "We say a student is being bullied when another student or group of students says or does nasty and unpleasant things to him or her. It is also bullying when a pupil is teased repeatedly in a way he or she doesn't like. But it is not bullying when two students of about the same strength quarrel or fight." Victimization was assessed by two parallel questions asking respondents, "How often have you been bullied in school in the past four weeks?" and "How often have you been bullied away from school in the past four weeks?" Similarly, bullying was assessed by additional parallel questions. The frequency items were coded on a five-point scale ranging from not at all to most days. Respondents were classified as "never victimized," "victimized less than weekly," or "victimized frequently" (at least three to four times in the past 4 weeks). Similarly, respondents were classified as "never bullying," "bullying less than weekly," or "bullying frequently." The reliability (Cronbach's $\alpha$ ) of the questionnaire is .63 .

\section{Statistical Analysis}

A series of logistic regression models was used to determine whether depression, ideation, and attempts (as dichotomized outcomes) were associated with bullying behavior (less than weekly and frequently). The categories "never victimized" and "never bully" were the reference groups in these analyses. The analyses were conducted separately for events in and away from school and were adjusted for schools, grade, and gender.

Another series of logistic regression analyses was conducted to examine gender differences in the association between bullying behavior with depression, ideation, and attempts. These regression analyses were first conducted separately for boys and girls and were adjusted for schools and grade. To avoid small numbers, we combined having been victimized in and away from school and combined bullying in the two locations. This was justified by the relationship between being victimized/bullying others in and away from school $\left(r_{\text {victimized in and away from school }}=0.42, p<.01 ; r_{\text {bully }}\right.$ in and away from school $=0.54, p<.01)$. Interactions between gender and bullying behaviors were examined in additional models. A power analysis revealed sufficient power $(>0.80)$ to detect the interactions.

Finally, the relationship of the three outcome measures to the co-occurrence of being victimized and bullying others was examined. Respondents were classified into five mutually exclusive categories: "never bullies nor victims," "infrequent bullies or victims," "frequently victims only," "frequently bullies only," or "frequently both bullies and victims (bully-victims)." Respondents who were neither victims nor bullies served as the reference group. If a student was a bully and a victim, we used the maximum score to decide to which group he or she belonged. Interactions between gender and bullying behaviors were examined in additional models.

We chose not to include random effects for school or class in the regression analyses because the sample clusters (school) and randomization unit (class within school) had little impact on the outcomes or correlates (gender, depression, serious suicide ideation/ behavior, bullying behavior), as indicated by the intraclass coefficients, which were close to zero (intraclass coefficients $<0.07$ ). Moreover, meaningful differences between results of random-effects regression models and our analysis were not anticipated because we had many units of randomization (181 classes) of relatively small average size (Murray, 1998). Analyses were conducted with the SPSS software package, version 12 . Results were considered significant at $\alpha<.05$.

\section{RESULTS}

\section{Prevalence of Bullying Behavior}

Victimization and bullying were more prevalent in school compared with away from school. Approximately $20 \%$ of the students reported being victims in school (Table 1). Significantly fewer (10.4\%) reported being victims away from school $(z=11.12, p<.001)$. Similarly, $\approx 25 \%$ of the students reported bullying in school, whereas significantly fewer $(\approx 15 \%)$ reported bullying away from school $(z=10.41, p<.001)$. 
TABLE 1

Prevalence of Bullying Behavior In and Out of School

\begin{tabular}{|c|c|c|c|c|}
\hline Bullying Behavior & $\begin{array}{c}\text { Boys }(n=1,272), \\
\%(\text { no. })\end{array}$ & $\begin{array}{l}\text { Girls }(n=908), \\
\%(\text { no. })\end{array}$ & $\begin{array}{c}\text { Total }(N=2,180), \\
\% \text { (no.) }\end{array}$ & $\begin{array}{c}\chi^{2} \text { Gender } \\
\text { Differences; } p\end{array}$ \\
\hline Victim in school & & & & $13.91 ; .001$ \\
\hline Never & $77.3(983)$ & $83.1(755)$ & $79.7(1,738)$ & \\
\hline Less than weekly & $14.9(189)$ & $12.3(112)$ & $13.8(301)$ & \\
\hline Frequently & $7.9(100)$ & $4.5(41)$ & $6.5(141)$ & \\
\hline Victim away from school & & & & $1.43 ; .49$ \\
\hline Never & $89.9(1,143)$ & $89.3(812)$ & $89.6(1,955)$ & \\
\hline Less than weekly & $7.6(97)$ & $8.7(79)$ & $8.1(176)$ & \\
\hline Frequently & $2.5(32)$ & $2.0(18)$ & $2.3(50)$ & \\
\hline Bully others in school & & & & $73.26 ;<.001$ \\
\hline Never & $68.7(872)$ & $84.5(768)$ & $75.3(1,640)$ & \\
\hline Less than weekly & $20.6(262)$ & $11.3(103)$ & $16.8(365)$ & \\
\hline Frequently & $10.7(136)$ & $4.2(38)$ & $8.0(174)$ & \\
\hline Bully others away from school & & & & $24.07 ;<.001$ \\
\hline Never & $81.9(1,042)$ & $89.1(810)$ & $84.9(1,852)$ & \\
\hline Less than weekly & $11.7(149)$ & $8.0(73)$ & $10.2(222)$ & \\
\hline Frequently & $6.4(82)$ & $2.9(26)$ & $4.9(108)$ & \\
\hline
\end{tabular}

Boys were significantly more likely than girls to be victims in school and to be bullies in and away from school. There were no significant differences between boys and girls in the frequency of being victims away from school.

Association of Bullying Behavior With Depression, Serious Suicidal Ideation, and Suicide Attempts

Students who were involved in bullying behavior in or out of school, whether as a victim or a bully, were at significantly higher risk for depression, serious suicidal ideation (SSI), and suicide attempts compared with students who were never victims or bullies (Table 2). The more frequent the involvement in bullying behavior was (whether as a victim or a bully), the more likely the student was depressed, had SSI, or had attempted suicide. For example, students who were frequently victims in or away from school were seven times more likely to be depressed compared with students who were never victims. Students who were victims infrequently in or away from school were two to three times more likely to be depressed. Students who frequently bullied others in or away from school were three times more likely to be depressed compared with students who never bullied others. Students who bullied others infrequently were approximately two times more likely to be depressed. A similar pattern was found for SSI and suicide attempts. The only exception to the pattern of greater risk being associated with greater bullying involvement was for victimization away from school and suicide attempts; however, the number of participants who were frequently victimized away from school and made an attempt was too small $(n=3)$ to yield adequate statistical power.

\section{Gender Differences in Associations Between Psychopathology and Bullying Behavior}

Frequently victimized boys were more likely to be depressed, have SSI, and attempt suicide than boys who were never victimized ( $p=.000, p=.000, p=.058$, respectively; Table 3). Boys who were infrequently victimized were more likely to attempt suicide but were not more likely to be depressed or have SSI than boys who were never victimized. Boys who bullied others frequently were more likely to be depressed and have SSI but were not more likely to attempt suicide compared with boys who never bullied others. Boys who bullied others infrequently were not at a higher risk for depression, SSI, or suicide attempts.

Among girls, any involvement in bullying behaviors was associated with a higher risk for depression, SSI, and suicide attempts. Girls who were victimized, whether infrequently or frequently, were more likely to be depressed, have SSI, and attempt suicide than girls who were never victims. Girls who bullied others, whether infrequently or frequently, were more likely to be depressed, have SSI, and attempt suicide compared with girls who never bullied others. 
TABLE 2

Association of Bullying Behavior With Depression, Suicidal Ideation, and Suicide Attempts

\begin{tabular}{|c|c|c|c|c|c|c|c|c|c|c|c|c|}
\hline & \multicolumn{3}{|c|}{ Victim in School } & \multicolumn{3}{|c|}{ Victim Away From School } & \multicolumn{3}{|c|}{ Bully Others in School } & \multicolumn{3}{|c|}{ Bully Others Away From School } \\
\hline & & Less Than & & & Less Than & & & Less Than & & & Less Than & \\
\hline & $\begin{array}{c}\text { Never } \\
(n=1738)^{a}\end{array}$ & $\begin{array}{c}\text { Weekly } \\
(n=301)^{a}\end{array}$ & $\begin{array}{l}\text { Frequently } \\
(n=141)^{a}\end{array}$ & $\begin{array}{c}\text { Never } \\
(n=1955)^{a}\end{array}$ & $\begin{array}{c}\text { Weekly } \\
(n=176)^{a}\end{array}$ & $\begin{array}{l}\text { Frequently } \\
(n=50)^{a}\end{array}$ & $\begin{array}{c}\text { Never } \\
(n=1640)^{a}\end{array}$ & $\begin{array}{c}\text { Weekly } \\
(n=365)^{a}\end{array}$ & $\begin{array}{l}\text { Frequently } \\
(n=174)^{a}\end{array}$ & $\begin{array}{c}\text { Never } \\
(n=1852)^{a}\end{array}$ & $\begin{array}{c}\text { Weekly } \\
(n=222)^{a}\end{array}$ & $\begin{array}{l}\text { Frequently } \\
(n=108)^{a}\end{array}$ \\
\hline \multicolumn{13}{|l|}{ Depression } \\
\hline$\%(n)$ & $7.3(127)$ & $15.3(46)$ & $29.5(41)$ & $8.2(160)$ & $20.8(36)$ & $36.0(18)$ & $8.5(139)$ & $11.8(43)$ & $18.6(32)$ & $8.5(157)$ & $15.4(34)$ & $21.5(23)$ \\
\hline $\mathrm{OR}^{b}$ & & $2.63^{* * *}$ & $7.35^{* * *}$ & & $2.98^{* * *}$ & $7.72^{* * *}$ & & $1.82^{* * *}$ & $3.46^{* * *}$ & & $2.26^{* * *}$ & $3.82^{* * *}$ \\
\hline$(95 \% \mathrm{CI})$ & & $(1.80-3.82)$ & $(4.75-11.38)$ & & $(1.97-4.50)$ & $(4.12-14.46)$ & & $(1.25-2.66)$ & $(2.20-5.46)$ & & $(1.49-3.42)$ & $(2.27-6.41)$ \\
\hline \multicolumn{13}{|c|}{ Serious suicidal ideation } \\
\hline$\%(n)$ & $2.8(49)$ & $7.0(21)$ & $11.5(16)$ & $3.1(61)$ & $10.3(18)$ & $14.3(7)$ & $3.1(50)$ & $6.4(23)$ & $7.6(13)$ & $3.2(59)$ & $5.9(13)$ & $13.1(14)$ \\
\hline $\mathrm{OR}^{b}$ & & $2.79^{* * *}$ & $5.41^{* * *}$ & & $3.62^{* * *}$ & $5.88^{* * *}$ & & $2.62^{* * *}$ & $3.44^{* * *}$ & & $2.15^{*}$ & $5.81^{* * *}$ \\
\hline$(95 \% \mathrm{CI})$ & & $(1.64-4.75)$ & $(2.94-9.96)$ & & $(2.07-6.32)$ & $(2.50-13.81)$ & & $(1.56-4.42)$ & $(1.78-6.65)$ & & $(1.15-4.02)$ & $(3.04-11.11)$ \\
\hline \multicolumn{13}{|c|}{ Suicide attempts } \\
\hline$\%(n)$ & $3.2(56)$ & $7.4(22)$ & $10.8(15)$ & $3.9(75)$ & $8.7(15)$ & $6.1(3)$ & $3.4(56)$ & $6.4(23)$ & $8.2(14)$ & $3.4(63)$ & 7.8 (17) & $12.3(13)$ \\
\hline $\mathrm{OR}^{b}$ & & $2.66^{* * *}$ & $4.49^{* * *}$ & & $2.14^{*}$ & 1.73 & & $2.45^{* *}$ & $3.64^{* * *}$ & & $2.70^{* *}$ & $5.38^{* * *}$ \\
\hline$(95 \% \mathrm{CI})$ & & $(1.58-4.47)$ & $(2.40-8.38)$ & & $(1.19-3.86)$ & $(0.52-5.77)$ & & $(1.46-4.12)$ & $(1.91-6.94)$ & & $(1.53-4.79)$ & $(2.74-10.55)$ \\
\hline
\end{tabular}

Note: $\mathrm{OR}=$ odds ratio; $\mathrm{CI}=$ confidence interval.

a n's vary slightly because of missing data.

${ }^{b}$ Adjusted for schools attended, grade, and gender.

${ }^{*} p<.05 ;{ }^{* *} p<.01 ;{ }^{* * *} p<.001$. 
Significant interactions between gender and the bullying-related variables indicated that girls who bullied others frequently were at significantly higher risk for depression and suicide attempts than comparable boys (odds ratio $[\mathrm{OR}]=3.93,95 \%$ confidence interval $[\mathrm{CI}]=1.6-9.4, p=.002$; OR $4.08,95 \% \mathrm{CI}$ $1.2-13.8, p=.024$, respectively). Interactions between bullying behavior and gender were not significant with regard to suicidal ideation.

\section{Impact of Co-occurrence of Bullying and Victimization}

Among boys, $2.5 \%$ were frequently both bullies and victims (bully-victims), $6.1 \%$ were frequently victims only, $10.4 \%$ were frequently bullies only, and $28.1 \%$ were infrequently bullies or victims (Table 4). Among girls, nearly $1 \%$ were frequently bully-victims, $4.5 \%$ were frequently victims only, $4.4 \%$ were frequently bullies only, and $22.1 \%$ were infrequently bullies or victims. A significantly greater proportion of girls (nearly 70\%) than boys $(52.8 \%)$ were neither bullies nor victims $\left(\chi^{2}=62.55 ; d f=5, p<.001\right)$.

Boys who were frequently bully-victims were more likely to be depressed and have SSI than boys who were not involved in bullying behavior. The small number of boys who were bully-victims and made a suicide attempt $(n=1)$ precluded a meaningful examination of the risk of attempts. Boys who frequently bullied others only were not more likely to be depressed, have SSI, or attempt suicide compared with boys who never bullied others. Boys who were frequently victims only were more likely to be depressed, have SSI, and attempt suicide than boys who were never victimized. Boys who were infrequently involved were more likely to attempt suicide but not more likely to be depressed or have SSI than boys who were never involved.

Among girls, any involvement in bullying behavior increased the risk for depression, SSI, and suicide attempts. Girls who were frequently bully-victims were

TABLE 3

Association of Bullying Behavior With Depression, Suicidal Ideation, and Suicide Attempts by Gender

\begin{tabular}{|c|c|c|c|c|c|c|}
\hline & \multicolumn{3}{|c|}{ Victim In and Out of School } & \multicolumn{3}{|c|}{ Bully Others In and Out of School } \\
\hline & $\begin{array}{c}\text { Never } \\
\left(n \mathrm{M}=935 ;^{a}\right. \\
n \mathrm{~F}=716)\end{array}$ & $\begin{array}{l}\text { Less Than Weekly } \\
\qquad\left(n \mathrm{M}=225 ;^{a}\right. \\
\quad n \mathrm{~F}=139)\end{array}$ & $\begin{array}{l}\text { Frequently } \\
\left(\begin{array}{c}n \mathrm{M}=109 ;^{a} \\
n \mathrm{~F}=49)\end{array}\right.\end{array}$ & $\begin{array}{c}\text { Never } \\
\left(n \mathrm{M}=815 ;^{a}\right. \\
n \mathrm{~F}=725)\end{array}$ & $\begin{array}{l}\text { Less Than Weekly } \\
\qquad \begin{array}{c}\left(n \mathrm{M}=291 ;^{a}\right. \\
n \mathrm{~F}=131)\end{array}\end{array}$ & $\begin{array}{l}\text { Frequently } \\
\begin{array}{c}\left(n \mathrm{M}=163 ;^{a}\right. \\
n \mathrm{~F}=48)\end{array}\end{array}$ \\
\hline \multicolumn{7}{|l|}{ Depression } \\
\hline Male, \% (no.) & $4.1(38)$ & $6.7(15)$ & $21.1(23)$ & $4.8(39)$ & $7.2(21)$ & $9.8(16)$ \\
\hline $\mathrm{OR}^{b}$ & & 1.74 & $6.45^{* * *}$ & & 1.55 & $2.10^{*}$ \\
\hline $95 \%$ CI & & $0.94-3.23$ & $3.65-11.42$ & & $0.89-2.70$ & $1.12-3.94$ \\
\hline Female, \% (no.) & $10.5(75)$ & $27.3(38)$ & $51.0(25)$ & $11.3(82)$ & $23.7(31)$ & $52.1(25)$ \\
\hline $\mathrm{OR}^{b}$ & & $3.25^{* * *}$ & $9.73^{* * *}$ & & $2.43^{* * *}$ & $8.39^{* * *}$ \\
\hline $95 \% \mathrm{CI}$ & & $2.08-5.08$ & $5.23-18.10$ & & $1.52-3.88$ & $4.53-15.53$ \\
\hline \multicolumn{7}{|c|}{ Serious suicidal ideation } \\
\hline Male, \% (no.) & $1.9(18)$ & $3.1(7)$ & $10.1(11)$ & $2.1(17)$ & $3.8(11)$ & $4.9(8)$ \\
\hline $\mathrm{OR}^{b}$ & & 1.69 & $5.88^{* * *}$ & & 1.92 & $2.57^{*}$ \\
\hline $95 \% \mathrm{CI}$ & & $0.70-4.12$ & $2.67-12.92$ & & $0.88-4.18$ & $1.07-6.20$ \\
\hline Female, \% (no.) & $3.3(24)$ & $13.7(19)$ & $14.3(7)$ & $3.7(27)$ & $10.0(13)$ & $20.8(10)$ \\
\hline $\mathrm{OR}^{b}$ & & $4.75^{* * *}$ & $5.26^{* * *}$ & & $3.13^{* *}$ & $7.18^{* * *}$ \\
\hline $95 \%$ CI & & $2.50-9.00$ & $2.10-13.17$ & & $1.54-6.34$ & $3.17-16.25$ \\
\hline \multicolumn{7}{|l|}{ Suicide attempts } \\
\hline Male, \% (no.) & $1.8(17)$ & $4.5(10)$ & $4.6(5)$ & $2.0(16)$ & $3.4(10)$ & $3.7(6)$ \\
\hline $\mathrm{OR}^{b}$ & & $2.64^{*}$ & 2.70 & & 1.86 & 2.07 \\
\hline $95 \% \mathrm{CI}$ & & $1.18-5.90$ & $0.97-7.55$ & & $0.83-4.18$ & $0.78-5.51$ \\
\hline Female, \% (no.) & $5.0(36)$ & $10.9(15)$ & $20.0(10)$ & $4.5(33)$ & $10.9(14)$ & $29.2(14)$ \\
\hline $\mathrm{OR}^{b}$ & & $2.30^{*}$ & $4.98^{* * *}$ & & $2.72^{* *}$ & $8.91^{* * *}$ \\
\hline $95 \% \mathrm{CI}$ & & $1.21-4.38$ & $2.24-11.08$ & & $1.38-5.34$ & $4.23-18.77$ \\
\hline
\end{tabular}

Note: $\mathrm{M}=$ male; $\mathrm{F}=$ female; $\mathrm{OR}=$ odds ratio; $\mathrm{CI}=$ confidence interval.

${ }^{a}$ Numbers vary slightly because of missing data.

${ }^{b}$ Adjusted for schools attended and grade.

${ }^{*} p<.05 ;{ }^{* *} p<.01 ;{ }^{* * *} p<.001$. 
TABLE 4

Co-occurrence of Bullying and Victimization: Association With Depression, Suicidal Ideation, and Suicide Attempts

\begin{tabular}{|c|c|c|c|c|c|}
\hline & $\begin{array}{l}\text { Neither Bully } \\
\text { nor Victim }^{a} \\
\left(n \mathrm{M}=671 ;^{b}\right. \\
n \mathrm{~F}=615)\end{array}$ & $\begin{array}{l}\text { Infrequently } \\
\text { Bully or Victim } \\
\left(n \mathrm{M}=357 ;^{b}\right. \\
n \mathrm{~F}=200)\end{array}$ & $\begin{array}{l}\text { Frequently } \\
\text { Victim Only } \\
\begin{array}{c}\left(n \mathrm{M}=78 ;^{b}\right. \\
n \mathrm{~F}=41)\end{array}\end{array}$ & $\begin{array}{l}\text { Frequently } \\
\text { Bully Only } \\
\begin{array}{c}\left(n \mathrm{M}=132{ }^{b}\right. \\
n \mathrm{~F}=40)\end{array}\end{array}$ & $\begin{array}{l}\text { Frequently Both } \\
\text { Bully and Victim } \\
\qquad \begin{array}{c}\left(n \mathrm{M}=32 ;^{b}\right. \\
n \mathrm{~F}=9)\end{array}\end{array}$ \\
\hline \multicolumn{6}{|l|}{ Depression } \\
\hline Male, \% (no.) & $3.6(24)$ & $5.6(20)$ & $20.5(16)$ & $6.8(9)$ & $22.6(7)$ \\
\hline $\mathrm{OR}^{c}$ & & 1.34 & $6.00^{* * *}$ & 1.63 & $6.36^{* * *}$ \\
\hline $95 \% \mathrm{CI}$ & & $0.75-2.40$ & $3.08-11.70$ & $0.74-3.57$ & $2.50-16.17$ \\
\hline Female, \% (no.) & $9.1(56)$ & $19.0(38)$ & $46.3(19)$ & $47.5(19)$ & $75.0(6)$ \\
\hline $\mathrm{OR}^{c}$ & & $2.38^{* * *}$ & $9.29^{* * *}$ & $8.81^{* * *}$ & $32.15^{* * *}$ \\
\hline $95 \% \mathrm{CI}$ & & $1.52-3.72$ & $4.71-18.35$ & $4.46-17.43$ & $6.29-164.30$ \\
\hline \multicolumn{6}{|c|}{ Serious suicidal ideation } \\
\hline Male, \% (no.) & $1.8(12)$ & $2.8(10)$ & $7.7(6)$ & $2.3(3)$ & $16.1(5)$ \\
\hline $\mathrm{OR}^{c}$ & & 1.56 & $4.54^{* *}$ & 1.29 & $9.93^{* * *}$ \\
\hline $95 \%$ CI & & $0.67-3.61$ & $1.66-12.44$ & $0.36-4.68$ & $3.23-30.54$ \\
\hline Female, \% (no.) & $2.9(18)$ & $8.5(17)$ & $12.5(5)$ & $20.5(8)$ & $22.2(2)$ \\
\hline $\mathrm{OR}^{c}$ & & $3.29^{* *}$ & $5.26^{* *}$ & $9.04^{* * *}$ & $10.00^{* *}$ \\
\hline $95 \% \mathrm{CI}$ & & $1.65-6.57$ & $1.81-15.29$ & $3.56-22.97$ & $1.86-53.64$ \\
\hline \multicolumn{6}{|l|}{ Suicide attempts } \\
\hline Male, \% (no.) & $1.3(9)$ & $3.7(13)$ & $5.1(4)$ & $3.8(5)$ & $6.5(1)$ \\
\hline $\mathrm{OR}^{c}$ & & $2.71^{*}$ & $3.88^{*}$ & 2.96 & 2.45 \\
\hline $95 \% \mathrm{CI}$ & & $1.17-6.28$ & $1.17-12.85$ & $0.97-9.05$ & $0.30-20.14$ \\
\hline Female, \% (no.) & $3.9(24)$ & $8.1(16)$ & $17.1(7)$ & $28.2(11)$ & $33.3(3)$ \\
\hline $\mathrm{OR}^{c}$ & & $2.25^{*}$ & $5.43^{* * *}$ & $9.89^{* * * b}$ & $12.66^{* *}$ \\
\hline $95 \% \mathrm{CI}$ & & $1.16-4.37$ & $2.11-13.92$ & $4.26-22.95$ & $2.74-58.48$ \\
\hline
\end{tabular}

Note: $\mathrm{M}=$ male; $\mathrm{F}$ = female; $\mathrm{OR}$ = odds ratio; $\mathrm{CI}$ = confidence interval.

${ }^{a}$ Reference group for the indicated significance.

${ }^{b}$ Numbers vary slightly because of missing data.

${ }^{c}$ Adjusted for schools attended and grade.

${ }^{*} p<.05 ;{ }^{* *} p<.01 ;{ }^{* * *} p<.001$.

32 times more likely to be depressed and 10 to 12 times more likely to have SSI or to attempt suicide compared with girls who were not involved in bullying behavior. Girls who were frequently bullies only or were frequently victims only were more likely to be depressed, have SSI, or attempt suicide compared with girls who never bullied others or who were never victimized, respectively. Even girls who were infrequently bullies or victims were two to three times more likely to be depressed, have SSI, or attempt suicide.

Significant interactions between gender and the bullying-related variables indicated that girls who frequently bullied others only were at significantly higher risk for depression and SSI than comparable boys (OR 5.29, 95\% CI 1.9-14.9, $p=.002$; OR 6.83, $95 \%$ CI 1.4-33.2, $p=.017$, respectively). Interactions between bullying behavior and gender were not significant with regard to suicide attempts.

\section{DISCUSSION}

This study found an association between bullying behavior and depression, SSI, and suicide attempts among high school students. Approximately $9 \%$ of the sample reported being frequently victimized, and 13\% reported bullying others frequently. These rates are similar to previous reports (Kaltiala-Heino et al., 1999; Nansel et al., 2001).

Most bullying behavior occurred in school compared with away from school, as found in other studies (Williams et al., 1996; Wolke et al., 2001). Bullying behavior away from school, however, was still prevalent among high school students (25.5\%). Bullying behavior was more prevalent among boys than girls, consistent with previous reports (Kumpulainen et al., 1998; Wolke et al., 2001). The decrease in the prevalence of bullying behavior from childhood to adolescence (Olweus, 1991) seems to indicate that 
bullying behaviors are less normative in high schools and that those adolescents still engaged in bullying behavior in high school may be more disturbed. As such, our findings can be generalized only to high school students.

Depression, SSI, and suicide attempts were significantly associated with victimization and with bullying others both in and away from school. Higher exposures to being victimized or bullying others generally were related to higher risk of depression, suicidal ideation, and suicide attempts, yet infrequent involvement in bullying behavior also was related to increased risk of depression and suicidality, particularly among girls.

Our findings are consistent with reports that bullies, not just victims, are at higher risk of depression, ideation, and attempts (Forero et al., 1999; KaltialaHeino et al., 1999; Kaltiala-Heino et al., 2000; Kumpulainen et al., 2000; Roland, 2002; Seals and Young, 2003; Wolke et al., 2001). Moreover, our findings replicate reports that the most disturbed group are the bully-victims (Austin and Joseph, 1996; Juvonen et al., 2003; Kaltiala-Heino et al., 1999; Kim et al., 2005). Although our findings are not consistent with reports that depression is rare among adolescent bullies (Camodeca et al., 2005; Fekkes et al., 2004; Juvonen et al., 2003), these studies did not account for gender differences. The inconsistent results may be explained by the gender differences we found. Our results suggest that there is a different threshold in which bullying is associated with depression and suicidality among girls and boys. Girls who bullied others were at risk for depression, ideation, and attempts even when the bullying was infrequent. Among boys, however, only frequent bullying was associated with depression, ideation, and attempts. Infrequent bullying among boys may be a more normative behavior, consistent with reports that the level of aggression is higher among boys compared with girls (Achenbach and Edelbrock, 1981). The gender differences in the association with bullying may be understood by the findings of Wasserman et al. (2005), indicating that female adolescents who demonstrate conduct problems are at higher risk of affective disorders than comparable male adolescents. These girls were found to be more aggressive but also more depressed than boys with conduct problems. Bullying behavior could be another example of a "gender paradox" (Tiet et al., 2001; Wasserman et al., 2005) in which girls are less likely to be bullies, but when they are they have a more severe impairment than their male counterparts.

The results suggest a different gender threshold in victimization as well. Among girls, victimization at any frequency increased the risk of depression, ideation, and attempts. Among boys, only frequent victimization increased the risk of depression and ideation, although infrequent victimization was associated with an increased risk of attempts. These findings contradict reports that only female victims are at greater risk for depression and ideation (Kim et al., 2005; van der Wal et al., 2003).

\section{Limitations}

One limitation was the use of a convenient, rather than a random, sample of schools. The schools were suburban and predominantly white, limiting the generalizability to urban and more ethnically or socioeconomically diverse settings. However, studies reporting on ethnicity and socioeconomic status as factors in bullying behavior have shown inconsistent results. Research in elementary school students suggests that socioeconomic status is inversely related to bullying and victimization (Veenstra et al., 2005; Wolke et al., 2001). Olweus (1999), in contrast, found that bullying was unrelated to social class. Seals and Young (2003) found no statistically significant differences in bullying involvement based on ethnicity. However, Nansel et al. (2001) found that Hispanic youth reported higher involvement in bullying of others, whereas black youth reported being bullied with less frequency. We had a similar finding: Hispanics were slightly more likely to bully others in school compared with other ethnic groups. The small number of minority students in the present study precludes the examination of the association of bullying behaviors with depression, SSI, and suicide attempts by race. Further studies should include these analyses. Second, only two thirds of eligible subjects participated in the study. Despite no significant differences between participants and nonparticipants in demographic factors (e.g., sex, grade level, ethnicity), the same cannot be said about clinical factors (e.g., BDI and SIQ-JR scores). Third, data on bullying were based on self-reports. Information about bullying also can be obtained from peers, parents, and teachers. Fourth, we found a cross-sectional association between bullying and depression/suicidality, but causality cannot be determined. 


\section{Clinical Implications}

Our findings suggest that bullying behavior in and away from high school is a prevalent problem among adolescents. Being a victim or a perpetrator appears to heighten the risk for depression, suicidal ideation, and suicide attempts. Our results emphasize that bullying may be a marker of suicidal behavior and that routine prevention of bullying should be considered part of any suicide prevention strategy. Both bullying behavior away from school and in-school bullying should be scrutinized. Mental health practitioners evaluating suicidal tendencies should consider bullying one of the potential risk factors. Conversely, in evaluations of students involved in bullying behavior, it is important to assess depression and suicidality.

\section{Disclosure: The authors have no financial relationships to disclose.}

\section{REFERENCES}

Achenbach TM, Edelbrock CS (1981), Behavioral problems and competencies reported by parents of normal and disturbed children aged four through sixteen. Monogr Soc Res Child Dev 46:1-82

Austin S, Joseph S (1996), Assessment of bully/victim problems in 8 to 11 year-olds. Br J Educ Psychol 66:447-456

Beck AT, Steer RA (1993), Manual for the Beck Depression Inventory. San Antonio, TX: The Psychological Corporation

Brent D (1987), Correlates of the medical lethality of suicide attempts in children and adolescents. J Am Acad Child Adolesc Psychiatry 26:87-91

Camodeca M, Goossens FA (2005), Aggression, social cognitions, anger and sadness in bullies and victims. J Child Psychol Psychiatry 46:186-197

Cleary SD (2000), Adolescent victimization and associated suicidal and violent behaviors. Adolescence 35:671-682

Davies M, Cunningham G (1999), Adolescent parasuicide in the Foyle area. Irish J Psychol Med 16:9-12

Eisenberg ME, Neumark-Sztainer D, Story M (2003), Associations of weight-based teasing and emotional well-being among adolescents. Arch Pediatr Adolesc Med 157:733-738

Fekkes M, Pijpers FI, Verloove-Vanhorick SP (2004), Bullying behavior and associations with psychosomatic complaints and depression in victims. J Pediatr 144:17-22

Forero R, McLellan L, Rissel C, Bauman A (1999), Bullying behavior and psychosocial health among school students in New South Wales, Australia: cross sectional survey. BMJ 319:344-348

Gould MS, King R, Greenwald S (1998), Psychopathology associated with suicidal ideation and attempts among children and adolescents. J Am Acad Child Adolesc Psychiatry 37:915-923

Gould MS, Marrocco FA, Kleinman M (2005), Evaluating iatrogenic risk of youth suicide screening programs: a randomized controlled trial. JAMA 293:1635-1643

Gould MS, Velting D, Kleinman M, Lucas C, Thomas JG, Chung M (2004), Teenagers' attitudes about coping strategies and help-seeking behavior for suicidality. J Am Acad Child Adolesc Psychiatry 43:1124-1133

Harris S (2005), Bullying at school among older adolescents. School Nurs Rev 22:18-21

Hawker DSJ, Boulton MJ (2000), Twenty years' research on peer victimization and psychosocial maladjustment: a meta-analytic review of cross-sectional studies. J Child Psychol Psychiatry 41:441-455

Ivarsson T, Broberg AG, Arvidsson T, Gillberg C (2005), Bullying in adolescents: psychiatric problems in victims and bullies as measured by the Youth Self Report (YSR) and the Depression Self-Rating Scale (DSRS). Nord J Psychiatry 59:365-373

Juvonen J, Graham S, Schuster MA (2003), Bullying among young adolescents: the strong, the weak, and the troubled. Pediatrics 112:1231-1237

Kaltiala-Heino R, Rimpela M, Marttunen M, Rimpela A, Rantanen P (1999), Bullying, depression, and suicidal ideation in Finnish adolescents: school survey. BMJ 319:348-351

Kaltiala-Heino R, Rimpela M, Rantanen P, Rimpela A (2000), Bullying at school: an indicator of adolescents at risk for mental disorders. J Adolesc 23:661-674

Keane EM, Dick RW, Bechtold DW, Manson SM (1996), Predictive and concurrent validity of the Suicidal Ideation Questionnaire among American Indian adolescents. J Abnorm Child Psychol 24:735-747

Kim YS, Koh YJ, Leventhal B (2005), School bullying and suicidal risk in Korean middle school students. Pediatrics 115:357-363

King CA, Ghaziuddin N, McGovern L, Brand E, Hill E, Naylor M (1996), Predictors of comorbid alcohol and substance abuse in depressed adolescents. J Am Acad Child Adolesc Psychiatry 35:743-751

King CA, Hill EM, Naylor M, Evans T, Shain B (1993), Alcohol consumption in relation to other predictors of suicidality among adolescent inpatient girls. J Am Acad Child Adolesc Psychiatry 32:82-88

King CA, Katz SH, Ghaziuddin N, Brand E, Hill E, McGovern L (1997), Diagnosis and assessment of depression and suicidality using the NIMH Diagnostic Interview Schedule for Children (DISC-2.3). J Abnorm Child Psychol 25:173-181

Kumpulainen K, Rasanen E (2000), Children involved in bullying at elementary school age: their psychiatric symptoms and deviance in adolescence: an epidemiological sample. Child Abuse Negl 24:1567-1577

Kumpulainen K, Rasanen E, Henttonen I (1998), Bullying and psychiatric symptoms among elementary school-age children. Child Abuse Negl 22:705-717

Meehan PJ, Lamb JA, Saltzman LE, O’Carroll PW (1992), Attempted suicide among young adults: progress toward a meaningful estimate of prevalence. Am I Psychiatry 149:41-44

Mills C, Guerin S, Lynch F, Daly I, Fitzpatrick C (2004), The relationship between bullying, depression and suicidal thoughts/behaviour in Irish adolescents. Ir J Psychol Med 21:112-116

Murray D (1998), Design and Analysis of Group-Randomized Trials. New York: Oxford University Press

Nansel TR, Overpeck M, Pilla RS, Ruan WJ, Simons-Morton B, Scheidt P (2001), Bullying behaviors among US youth: prevalence and association with psychosocial adjustment. JAMA 285:2094-2100

Neary A, Joseph S (1994), Peer victimization and its relationship to selfconcept and depression among schoolgirls. Personality Individual Differences 16:183-186

Olweus D (1991), Bully/victim problems among school children: Basic facts and effects of a school based intervention program. In: The development and treatment of childhood aggression, Pepler D, Rubin K, eds. Hillsdale, NJ: Lawrence Erlbaum Associates, pp 411-448

Olweus D (1999), Sweden. In: The Nature of School Bullying: A CrossNational Perspective, Smith PK, Morita Y, Junger-Tas J, Olweus D, Catalano R, Slee PT, eds. London: Routledge, pp 7-27

Reynolds W (1990), Development of a semi-structured clinical interview for suicidal behaviors in adolescents. Psychol Assess J Consult Clin Psychol 2:382-390

Reynolds W (1988), SIQ Professional Manual. Odessa, FL: Psychological Assessment Resources

Reynolds WM, Mazza JJ (1999), Assessment of suicidal ideation in innercity children and young adolescents: reliability and validity of the Suicidal Ideation Questionnaire-JR. School Psychol Rev 28:17-30

Rigby K, Slee P (1999), Suicidal ideation among adolescent school children, involvement in bully-victim problems, and perceived social support. Suicide Life Threat Behav 29:119-130

Roberts RE, Lewinsohn PM, Seeley JR (1991), Screening for adolescent depression: a comparison of depression scales. J Am Acad Child Adolesc Psychiatry 30:58-66

Roland E (2002), Bullying, depressive symptoms and suicidal thoughts. Educ Res 44:55-67 
Salmon G, James A, Smith DM (1998), Bullying in schools: self reported anxiety, depression, and self esteem in secondary school children. $B M J$ 317:924-925

Seals D, Young J (2003), Bullying and victimization: prevalence and relationship to gender, grade level, ethnicity, self-esteem, and depression. Adolescence 38:735-747

Shaffer D, Fisher P, Lucas CP, Dulcan MK, Schwab-Stone ME (2000), NIMH Diagnostic Interview Schedule for Children Version IV (NIMH DISC-IV): description, differences from previous versions, and reliability of some common diagnoses. J Am Acad Child Adolesc Psychiatry 39:28-38

Shaffer D, Scott M, Wilcox H (2004), The Columbia Suicide Screen: validity and reliability of a screen for youth suicide and depression. J Am Acad Child Adolesc Psychiatry 43:71-79

Sibthorpe B, Drinkwater J, Gardner K, Bammer G (1995), Drug use, binge drinking and attempted suicide among homeless and potentially homeless youth. Aust N Z J Psychiatry 29:248-256

Siemen JR, Warrington CA, Mangano EL (1994), Comparison of the Millon Adolescent Personality Inventory and the Suicide Ideation QuestionnaireJunior with an adolescent inpatient sample. Psychol Rep 75:947-950

Slee PT (1995), Bullying: health concerns of Australian secondary school students. Int J Adolesc Youth 5:215-224

Strober M, Green J, Carlson G (1981), Utility of the Beck Depression
Inventory with psychiatrically hospitalized adolescents. $J$ Consult Clin Psychol 49:482-483

Teri L (1982), The use of the Beck Depression Inventory with adolescents. J Abnorm Child Psychol 10:277-284

Tiet QQ, Wasserman GA, Loeber R, McReynolds LS, Miller LS (2001), Developmental and sex differences in types of conduct problems. J Child Fam Stud 10:181-197

van der Wal MF, de Wit CA, Hirasing RA (2003), Psychosocial health among young victims and offenders of direct and indirect bullying. Pediatrics 111:1312-1317

Veenstra R, Lindenberg S, Oldehinkel AJ, De Winter AF, Verhulst FC, Ormel J (2005), Bullying and victimization in elementary schools: a comparison of bullies, victims, bully/victims, and uninvolved preadolescents. Dev Psychol 41:672-682

Wasserman GA, McReynolds LS, Ko SJ, Katz LM, Carpenter JR (2005), Gender differences in psychiatric disorders at juvenile probation intake. Am J Public Health 95:131-137

Williams K, Chambers M, Logan S, Robinson D (1996), Association of common health symptoms with bullying in primary school children. BMJ 313:17-19

Wolke D, Woods S, Stanford K, Schulz H (2001), Bullying and victimization of primary school children in England and Germany: prevalence and school factors. Br J Psychol 92:673-696

Variation in the Diagnosis of Child Abuse in Severely Injured Infants Matthew Trokel, MD, Anthony Wadimmba, MB, ChB, John Griffith, PhD, Robert Sege, MD, PhD

Objective: Diagnosis of child abuse is difficult and may reflect patient, practitioner, and system factors. Previous studies have demonstrated potential lethal consequences if cases of abuse are missed and suggested a role for continuing medical education in improving the accuracy of diagnosis of suspected abuse. Although the majority of injured American children are treated at general hospitals, most published studies of severe injury resulting from child abuse have been conducted at children's hospitals. The objective of this study was to evaluate the role of hospital type in observed variations in the frequency of diagnosis of child physical abuse among children with high-risk injuries. Methods: Hospital discharge data were evaluated, and adjusted rates of abuse diagnosis were reported according to hospital type. A regression model estimated the number of cases of abuse that would have been diagnosed if all hospitals identified abuse as frequently as observed at pediatric specialty hospitals. This study consisted of children who were $<1$ year old and admitted to US hospitals in 1997 for treatment of traumatic brain injury or femur fracture, excluding penetrating trauma or motor-vehicle-related injury. A total of 2253 weighted cases were analyzed. Results: The proportion of patients with a medical diagnosis of child abuse varied widely between hospital types: $29 \%$ of the cases were diagnosed as abuse at children's hospitals compared with $13 \%$ at general hospitals. An estimated 178 infants (39\% of total) with these specific injuries would have been identified as abused had they been treated at children's rather than general hospitals. Conclusions: Hospital type was associated with large variations in the frequency of diagnosis of child abuse. This variation was not related to observed differences in the patients or their injuries and may result from systematic underdiagnosis in general hospitals. This result has implications for quality-improvement programs at general hospitals, where the majority of injured children in the United States receive emergent medical care. Pediatrics 2006;117:722-728. 